Original Article

\title{
FORMULATION AND EVALUATION OF METFORMIN HYDROCHLORIDE SUSTAINED RELEASE MATRIX TABLETS
}

\author{
SAHIDUL ALAM1 ${ }^{1}$, AMLAN BISHAL2 ${ }^{2}$ BRATATI BANDYOPADHYAY ${ }^{3}$
}

${ }^{1 * B}$ Bharat Technology, Uluberia, West Bengal, India, ${ }^{2,3}$ Department of Pharmaceutics, Bharat Technology, Uluberia, West Bengal, India Email: bishalamlan31@gmail.com

Received: 04 May 2021, Revised and Accepted: 02 Jul 2021

\begin{abstract}
Objective: Now a days as very few antidiabetic drugs are coming out of research and development and some existing drugs are showing several side effects when administered orally, multiple times in a day, hence change in the operation is a suitable and optimized way to make some drug more effective by slight alteration in the drug delivery. Matrix type drug delivery systems of an antidiabetic drug like Metformin Hydrochloride, is an interesting and promising option when developing an oral sustained release system
\end{abstract}

Methods: An appropriately designed controlled release drug delivery system can be a major advance towards solving problems concerning the targeting of a drug to a specific organ or tissue and controlling the rate of drug delivery to the target sites. This research work is made in designing of sustained release dosage form of Metformin Hydrochloride by wet granulation method employing both Xanthan Gum and Hydroxy Propyl Methyl Cellulose (HPMC K4M) as a rate controlling polymer.

Results: The development of oral sustained release systems has been a challenge to formulation scientists due to their inability to restrain and localize the system at targeted areas of the gastrointestinal tract. From all the formulation trial batches, formulation F7 shows the best results. It has been observed that HPMC K4M alone cannot give satisfactory drug release profile but the blend of HPMC K4M and Xanthan gum together give the best drug release kinetics.

Conclusion: The drug release mechanism from the matrix tablets follows Fickian diffusion with first order kinetics. Thus, sustained release matrix tablets of metformin hydrochloride can be expected to reduce the frequency of administration and decrease the dose dependent side effects

Keywords: Sustained release drug delivery, Matrix tablets, Diffusion, Rate limiting polymer, Anti-diabetic

(C) 2021 The Authors. Published by Innovare Academic Sciences Pvt Ltd. This is an open access article under the CC BY license (https://creativecommons.org/licenses/by/4.0/)

DOI: https://dx.doi.org/10.22159/ijcpr.2021v13i5.1899 Journal homepage: https://innovareacademics.in/journals/index.php/ijcpr

\section{INTRODUCTION}

Diabetes is one of the major causes of death and disability in the world. Diabetes is a long-lasting health condition that affects how our body turns food into energy. If you have diabetes your body does not make enough insulin that cause serious health problems, like heart disease, vision loss and kidney disease. Diabetes mellitus are be classified into two main types. First is type I or juvenile diabetes which is also called as insulin dependent diabetes and second type is type I or non-insulin dependent diabetes mellitus, this Type II diabetes is most common type of diabetes. Oral drug delivery is the most widely utilized route of administration among all the routes [nasal, ophthalmic, rectal, transdermal and parenteral routes] that have been explored for systemic delivery of drugs via pharmaceutical products of different dosage form. Oral route is considered most natural, uncomplicated, convenient and safe, due to its cease of administration, patient acceptance, and cost-effective manufacturing process [1-3]

Novel drug delivery systems are designed to achieve a continuous delivery of drugs at predictable and reproducible kinetics over an extended period of time in the circulation. The potential advantages of this concept include minimization of drug related side effects due to controlled therapeutic blood levels instead of oscillating blood levels, improved patient compliance due to reduced frequency of dosing and the reduction of the total dose of drug administered. Hence, the combination of both sustained release and control release properties in a delivery system would further enhance therapeutic efficacy $[4,5]$.

Controlled drug delivery systems have been developed which are capable of controlling the rate of drug delivery, sustaining the duration of therapeutic activity and/or targeting the delivery of drug to a tissue. Controlled drug delivery or modified drug delivery system. A controlled drug delivery system is usually designed to deliver the drug at particular rate. Safe and effective blood levels are maintained for a period as long as the system continues to deliver the drug. Controlled drug delivery usually results in substantially constant blood levels of the active ingredient as compared to the uncontrolled fluctuations observed when multiple doses of quick releasing conventional dosage forms are administered to a patient. Metformin Hydrochloride is the best drug of choice as a sustain release drug delivery system because a single dose of a Metformin we observe up to $12 \mathrm{~h}$ of therapeutic efficacy in our body. Metformin is an antihyperglycemic agent which improves glucose tolerance in patients with type 2 diabetes, lowering both basal and postprandial plasma glucose. Its pharmacologic mechanisms of action are different from other classes of oral antihyperglycemic agents. Metformin decreases hepatic glucose production, decreases intestinal absorption of glucose, and improves insulin sensitivity by increasing peripheral glucose uptake and utilization. Unlike sulfonylureas, metformin does not produce hypoglycemia in either patients with type 2 diabetes or normal subjects and does not cause hyperinsulinemia [6-8].

In our research article we have developed Metformin sustain release formulation using both Xanthan Gum and Hydroxy Propyl Methyl Cellulose (HPMC K4M) as a rate controlling polymer. Xanthan Gum is a natural polymer it has been used as a rate controlling agent to reduce the release pattern of the drug in the dissolution $[9,10]$.

\section{MATERIALS AND METHODS}

\section{Materials}

Metformin hydrochloride was purchased from Aarti Drugs, Polyvinylpyrrolidone (PVP K-30), Microcrystalline Cellulose (PH101) Xanthan gum purchased from Loba Chemie and Hydroxypropyl methyl cellulose purchased from Anhui Sunhere Pharmaceutical Excipients Co. Ltd. Talc and Magnesium stearate purchased from Loba Chemie. All other chemicals, solvents and reagents used were of analytical grade. 


\section{Methods}

\section{Drug excipient compatibility study}

To understand the physico-chemical characteristics of the active pharmaceutical ingredient (API) that is Metformin Hydrochloride, as well as inactive, drug excipients compatibility study is a very important process before going to design a prototype formula. Infrared spectra of pure drug and drug with polymers were recorded on a Fourier Transform Infra-Red Spectrophotometer available at Bengal School of Technology, Sugandha, Hooghly. The disc method was employed to study possible interactions between drug and polymers. Infrared spectrum was taken by scanning the sample in $\mathrm{KBr}$ (IR grade) disc and powder pellets produced were analyzed over a wave number range of 4000-400 cm-1. Transmittance spectra were recorded [17].

Preparation of matrix tablets using drug substance, polymers and other excipients

Metformin hydrochloride matrix tablets were prepared by wet granulation method using Polyvinylpyrrolidone (PVPK30) as granulating agent. Different formula was designed using varying proportions of hydrophilic polymer alone and in combination. The composition of matrix tablet is given in table 1 . Following steps were followed for preparation of granules:

Step 1 Sifting: Metformin hydrochloride was weighed accurately as per composition and sifted through 60\#, Microcrystalline cellulose (PH101), Xanthan gum, Hydroxypropyl methyl cellulose (HPMC $\mathrm{K} 4 \mathrm{M}$ ) were weighed accurately as per composition and sifted through 40\#.

Step 2 Dry mixing: Above sifted materials were collected in a polybag and mixed for 30 min to get a perfect homogenous mixture of drug and excipients. Here powder samples were collected after mixing to check the LOD of dry mix blend and also for blend uniformity.

Step 3 Preparation of binder solution: As per composition required quantity of purified water was taken in a beaker. Polyvinylpyrrolidone (PVP K30) was weighed accurately and added slowly to that beaker under stirring condition and continue stirring until it fully gets dissolved in purified water and form a clear translucent binder solution.

Step 4 Wet mixing: The binder solution next added slowly in dry mix blend in mix continuously until coherent wet mass is achieved. Granulation end point was determined by continuous visible observation on formation of granules.

Step 5 Wet sifting: Wet mass sifted through 10\# to get uniform size particles.

Step 6 Drying: After wet sifting granules were kept for air drying for 10 min and then kept inside a tray dryer at $50{ }^{\circ} \mathrm{C}$ until target LOD was achieved.

Step 7 Dry screening: Dried granules sifted through 20\# and collected in a double polythene lined container.

Step 8 Lubrication: Talc and Magnesium Stearate was weighed as per requirement and added to the above granules and mixed in a blender to get a lubricated blend.

Step 9 Compression: Tablets were compressed in a 10-station single rotary tablet press (Rimek Mini Press, IRM Enterprises Private Limited, Ahmedabad, India) equipped with 19.5 x $9.0 \mathrm{~mm}$, capsule shaped punch, having break-line on one side and plain on other side. A constant compression force required to produce hardness of tablets about $5-7 \mathrm{~kg} / \mathrm{cm}^{2}$. All physical parameters were checked and tablets were stored in airtight containers for further use.

Table 1: Composition of matrix tablets of metformin hydrochloride

\begin{tabular}{|c|c|c|c|c|c|c|c|}
\hline \multirow[t]{2}{*}{ Ingredients per tablets (mg) } & \multicolumn{7}{|c|}{ Composition (mg/s) of the prepared formulation } \\
\hline & F1 & F2 & F3 & F4 & F5 & F6 & F7 \\
\hline Metformin $\mathrm{HCl}$ & 500 & 500 & 500 & 500 & 500 & 500 & 500 \\
\hline Microcrystalline cellulose (PH 101) & 150 & 140 & 120 & 115 & 115 & 115 & 110 \\
\hline Hydroxypropyl methyl cellulose (HPMC K4M) & 180 & 180 & 200 & 200 & 100 & 100 & 100 \\
\hline Xanthan Gum & - & - & - & - & 100 & 110 & 110 \\
\hline Polyvinylpyrrolidone (PVP K30) & 10 & 20 & 20 & 25 & 25 & 25 & 25 \\
\hline Purified water & qs & qs & qs & qs & qs & qs & qs \\
\hline Talc & 5 & 5 & 5 & 5 & 5 & 5 & 5 \\
\hline Magnesium stearate & 5 & 5 & 5 & 5 & 5 & 5 & 10 \\
\hline Total weight & 850 & 850 & 850 & 850 & 850 & 850 & 850 \\
\hline
\end{tabular}

\section{Pre-compressional evaluation}

\section{Angle of repose}

Angle of repose helps to determine the effect of frictional force in a loose powder and cohesion between one particle to another. It is defined as the maximum angle possible between the surface of a pile of powder and the horizontal plane. Static angle of repose was determined by fixed funnel method or Fixed cone method. Angle of repose was calculated using following equation $[11,12]$.

$$
\tan \theta=\mathrm{h} / \mathrm{r}
$$

Where $\theta=$ angle of repose, $h=$ height of pile, $r=$ radius of pile base

\section{Compressibility Index}

Powder flow property can be measured by Compressibility index also known as Carr's Index. So, it is defined by the equation [13]

$$
\text { Carr's index }=\frac{\text { Tapped density }- \text { Bulk density }}{\text { Bulk density }} \times 100
$$

Where, Bulk density is the ratio of mass of powder to the bulk volume and Tapped density is the ratio of mass of powder to the tapped volume.
Table 2: Concentration v/s absorbance of metformin hydrochloride at 6.8 phosphate buffer

\begin{tabular}{ll}
\hline Concentration $(\boldsymbol{\mu g} / \mathbf{m l})$ & Absorbance \\
\hline 0 & 0 \\
1 & 0.079 \\
2 & 0.165 \\
3 & 0.246 \\
4 & 0.323 \\
5 & 0.407 \\
6 & 0.48 \\
7 & 0.562 \\
8 & 0.65 \\
\hline
\end{tabular}

\section{Evaluation of matrix tablets}

\section{Uniformity of drug content}

From each formulation ten tablets were weighed and triturated in a mortar to a fine powder. Powder equivalent to $500 \mathrm{mg}$ of metformin hydrochloride was extracted in $100 \mathrm{ml}$ of $\mathrm{pH} 6.8$ phosphate buffer and then the liquid was filtered using Whatman filter paper. Using UV-Visible spectrophotometer of Simadzu UV 1800 the drug content 
was determined by measuring the absorbance at $233 \mathrm{~nm}$, after proper dilution of the filtrate liquid with $\mathrm{pH} 6.8$ phosphate buffer.
The drug content was determined using standard calibration curve $[13,14]$

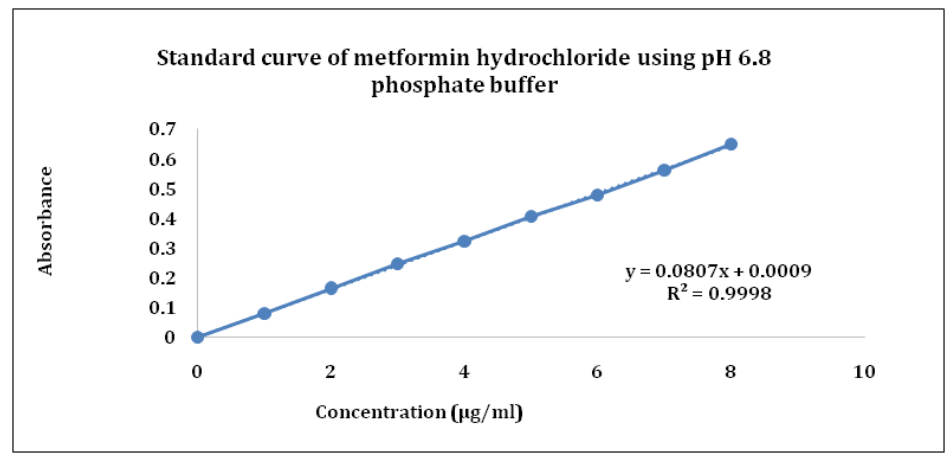

Fig. 1: Standard curve of metformin hydrochloride

\section{In vitro dissolution study}

The in vitro dissolution study of matrix tablets of metformin hydrochloride was performed using USP type II dissolution apparatus (LABINDIA) at a rotational speed of $50 \mathrm{rpm}$. In order to simulate gastrointestinal environment, the tablets were subjected to different dissolution media. The dissolution medium used were $900 \mathrm{ml}$ of $0.1(\mathrm{~N}) \mathrm{HCl}$ acidic buffer of $\mathrm{pH} 1.2$ buffer for first two hours and then pH 6.8 phosphate buffer for next ten hours. The dissolution medium was maintained at a temperature of $37 \pm 0.5^{\circ} \mathrm{C}$. At predetermined time intervals, $5 \mathrm{ml}$ of the sample solution was withdrawn from the dissolution apparatus and the samples were replaced with fresh dissolution medium to maintain sink conditions. The collected samples were filtered through a $0.45 \mu \mathrm{m}$ membrane filter and the drug content in each sample was analyzed by measuring absorbance at $233 \mathrm{~nm}$ after suitable dilution using UV-spectrophotometer (SHIMADZU UV 1800). Cumulative percentage of drug release was calculated using equation obtained from a calibration curve [14,17].

\section{In vitro drug release kinetic study}

To study the release mechanism of metformin hydrochloride from the sustained release matrix tablets, the invitro drug release data were fitted to the following the mathematical models $[3,4,16]$.

- Zero order release model $\mathrm{Qt}=\mathrm{Q} 0+\mathrm{K} 0 \mathrm{t}$

- First order release model $\log \mathrm{C}=\log \mathrm{C}_{0+} \mathrm{Kt} / 2.303$

- Higuchi's model Qt $=\mathrm{K}_{\mathrm{h}} \mathrm{t}^{1 / 2}$

- Kors Meyer-Peppas model Qt $/ Q \alpha=K_{p} t^{n}$

- Hixon-Crowell cube root model $\left(\mathrm{W}_{0}{ }^{1 / 3}-\mathrm{W}_{\mathrm{t}^{1 / 3}}\right)=\mathrm{K}_{\mathrm{h}} \mathrm{t}$

Where Q0, Qt and Q $\alpha$ are the amounts of drug dissolved initially, at time and at time infinite. $\mathrm{C}_{0}$ and $\mathrm{C}$ are the concentrations of drug initially and at time $t, W_{0}$ and $W_{t}$ are the amounts of drug in the pharmaceutical dosage form initially and at time $t$ and $K 0, K 1, K_{h}$ and $K_{p}$ refer to the rate constants obtained from the linear curves of the respective models. $n$ is the diffusional exponent that characterizes the mechanism of drug release. The values of the coefficient were calculated using regression analysis between $\log \mathrm{Qt} / \mathrm{Q} \alpha$ and $\log$ time. The diffusional exponent $\mathrm{n}$ value was obtained from the slope of the regression equation and $K_{p}$ was calculated from antilog of the intercept value.
If the value of $\mathrm{n}$ for a cylinder is $<0.45$ it suggests the Quasi Fickian release (diffusion controlled), if $n=45$ it suggests Fickian diffusion, if $0.45<\mathrm{n}<0.89$ it suggests anomalous diffusion or non-Fickian release (diffusion and polymer relaxation), if $n=0.89$ it suggests Case II release (only relaxation and swelling) and IF $n>0.89$ it suggests super Case II release (relaxation and erosion) for swellable systems. For cylindrical systems like tablets, the $n$ values of 0.45 and 0.89 represent pure diffusion or erosion release respectively $[4,16]$.

\section{RESULTS AND DISCUSSION}

\section{Characterization of powder}

For all the formulations the lubricated blend was evaluated for bulk density, tapped density, compressibility index, Hausner's ratio and Angle of repose and their values were shown in table 2 . The bulk densities and tapped densities were $0.77 \pm 0.01$ to $0.80 \pm 0.03 \mathrm{~g} / \mathrm{cm} 3$ and $0.87 \pm 0.02$ to $0.95 \pm 0.01 \mathrm{~g} / \mathrm{cm} 3$ respectively. Powder blend indicated fair to passable flow properties at the beginning and improve finally after increasing the concentration of lubricant. The values of angle of repose ranging from $27.65{ }^{\circ} \mathrm{C}$ to $38.29^{\circ} \mathrm{C}$. The Carr's compressibility index range for all the formulations were found to be $11.49 \%$ to $16.13 \%$, which indicates that the powder mixture has good flow properties. Hausner's ratio was also calculated, the ration was ranged between 1.12 and 1.23 .

\section{Evaluation of physical parameters}

By wet granulation technique Sustained release matrix tablets of metformin hydrochloride were prepared. Total seven formulations were prepared. The tablet weight variation, hardness, friability and content uniformity for each formulation are shown in table 3 . The weight variation test indicated that the percentage deviation of all tablet formulations was found to be within pharmacopeial acceptable limit. The hardness of all the tablets was within the range of $5.65 \pm 0.43$ to $6.59 \pm 0.37 \mathrm{~kg} / \mathrm{cm} 2$. The percentage weight loss in the friability test was found to be below $1 \%$ in all the cases indicated that all the tablets had good mechanical strength. The drug content in all the batches was determined by measuring absorbance of sample at $233 \mathrm{~nm}$ using double beam UV spectrophotometer (LAB INDIA). The content uniformity among different formulations was found to be higher and the drug content was more than $98 \%$ which indicates uniform drug distribution in all the formulations.

Table 3: Micromeritic properties of lubricated blend of all formulations

\begin{tabular}{|c|c|c|c|c|c|}
\hline Formulation & Bulk density $\left(\mathrm{g} / \mathrm{cm}^{3}\right)^{*}$ & Tapped density $\left(\mathrm{g} / \mathrm{cm}^{3}\right)^{*}$ & Compressibility index (\%) & Hausner's ratio & Angle of repose $\left({ }^{\circ} \mathrm{C}\right)$ \\
\hline F1 & $0.78 \pm 0.02$ & $0.93 \pm 0.01$ & 16.13 & 1.19 & 36.86 \\
\hline F2 & $0.79 \pm 0.01$ & $0.90 \pm 0.03$ & 12.22 & 1.23 & 38.29 \\
\hline F3 & $0.78 \pm 0.02$ & $0.90 \pm 0.02$ & 13.33 & 1.15 & 34.99 \\
\hline F4 & $0.80 \pm 0.03$ & $0.95 \pm 0.01$ & 15.79 & 1.19 & 35.94 \\
\hline F5 & $0.78 \pm 0.01$ & $0.90 \pm 0.02$ & 13.33 & 1.15 & 33.02 \\
\hline F6 & $0.78 \pm 0.02$ & $0.92 \pm 0.01$ & 15.22 & 1.17 & 32.00 \\
\hline F7 & $0.77 \pm 0.01$ & $0.87 \pm 0.02$ & 11.49 & 1.12 & 27.65 \\
\hline
\end{tabular}

*All values are expressed as mean \pm SD (Standard deviation), $\mathrm{n}=3$ 
Table 4: Physical properties of metformin hydrochloride sustained release matrix tablets of all formulation

\begin{tabular}{lllll}
\hline Formulation & Weight variation \pm SD (mg) & Hardness \pm SD $\left(\mathbf{k g} / \mathbf{c m}^{2}\right)$ & Friability (\%) & Content uniformity (\%) \\
\hline F1 & $850.52 \pm 2.58$ & $5.65 \pm 0.43$ & 0.78 & 98.96 \\
F2 & $850.35 \pm 2.47$ & $6.32 \pm 0.46$ & 0.65 & 9.02 \\
F3 & $849.79 \pm 2.32$ & $6.45 \pm 0.42$ & 0.54 & 99.56 \\
F4 & $850.30 \pm 1.97$ & $6.59 \pm 0.37$ & 0.81 & 100.56 \\
F5 & $850.36 \pm 1.03$ & $5.90 \pm 0.58$ & 0.89 & 101.23 \\
F6 & $850.86 \pm 2.52$ & $6.00 \pm 0.59$ & 0.48 & 100.05 \\
F7 & $850.44 \pm 0.76$ & $6.55 \pm 0.35$ & & \\
\hline
\end{tabular}

\section{In vitro dissolution study}

Release profile of Metformin hydrochloride from the matrix tablets was studied for first two hours in $\mathrm{pH} 1.2$ buffer and the next ten hours in pH 6.8 phosphate buffer. Total seven formulations were made with HPMC K4M alone and combination of xanthan gum with HPMCK4 in different ratios [15]. The results of dissolution studies indicated that the first four formulations with hydrophilic polymer, HPMC K4M alone released $43.68 \%, 42.84 \%, 37.80 \%$ and $33.88 \%$ of drug at the end of $2 \mathrm{~h}$ and $71.683,66.922$ and $64.962 \%$ of drug at the end of $6 \mathrm{~h}$. Formulations containing HPMCK4M in combination with Xanthan gum released 33.321, 30.241 and $27.721 \%$ at the end of $2 \mathrm{~h}$ and $99.124,100.524$ and $101.084 \%$ at the end of $12 \mathrm{~h}$. Marketed formulation Bigomet 500 SR tablet from Aristo Pharma showed $23.24 \%$ at $2 \mathrm{~h}$ and $98.48 \%$ at $12 \mathrm{~h}$. The comparative dissolution profile of all the formulations is given in fig. 1 . The results shown in fig. 1 indicate that the release rate of metformin hydrochloride from all the sustained release matrix tablets was dependent on concentration of release retardant contained in the tablet. The drug release rate was decreased from the tablets as the concentration of release retardant was increase. HPMC K4M alone could not control the release of metformin hydrochloride from the tablets because burst release was observed due to high dose of drug. Hydroxyl propyl methyl cellulose could control the drug release when combined with high molecular weight xanthan gum up to $12 \mathrm{~h}$. This may be due to the formation of thick gel layer around the tablets by quick hydration of xanthan gum. These results indicated that the Xanthan gum could control the release of metformin hydrochloride up to $12 \mathrm{~h}$. When it combined with hydroxy propyl methyl cellulose (semi synthetic). Following graphs represents the drug release kinetics.

Table 5: Zero order drug release

\begin{tabular}{|c|c|c|c|c|c|c|c|}
\hline \multirow[t]{2}{*}{ Time (h) } & \multicolumn{7}{|c|}{ Cumulative \% drug release } \\
\hline & F1 & F2 & F3 & F4 & F5 & F6 & F7 \\
\hline 0 & 0 & 0 & 0 & 0 & 0 & 0 & 0 \\
\hline 2 & 43.681 & 42.841 & 37.801 & 33.881 & 33.321 & 30.241 & 27.721 \\
\hline 4 & 54.882 & 55.722 & 49.842 & 47.322 & 44.801 & 46.202 & 45.362 \\
\hline 6 & 71.683 & 71.683 & 66.922 & 64.962 & 63.842 & 62.722 & 62.442 \\
\hline 8 & 90.443 & 88.483 & 82.603 & 82.323 & 80.083 & 78.963 & 80.643 \\
\hline 10 & 99.124 & 97.724 & 94.644 & 93.524 & 91.844 & 91.844 & 95.204 \\
\hline 12 & 101.364 & 100.524 & 103.044 & 99.964 & 99.124 & 100.524 & 101.084 \\
\hline
\end{tabular}

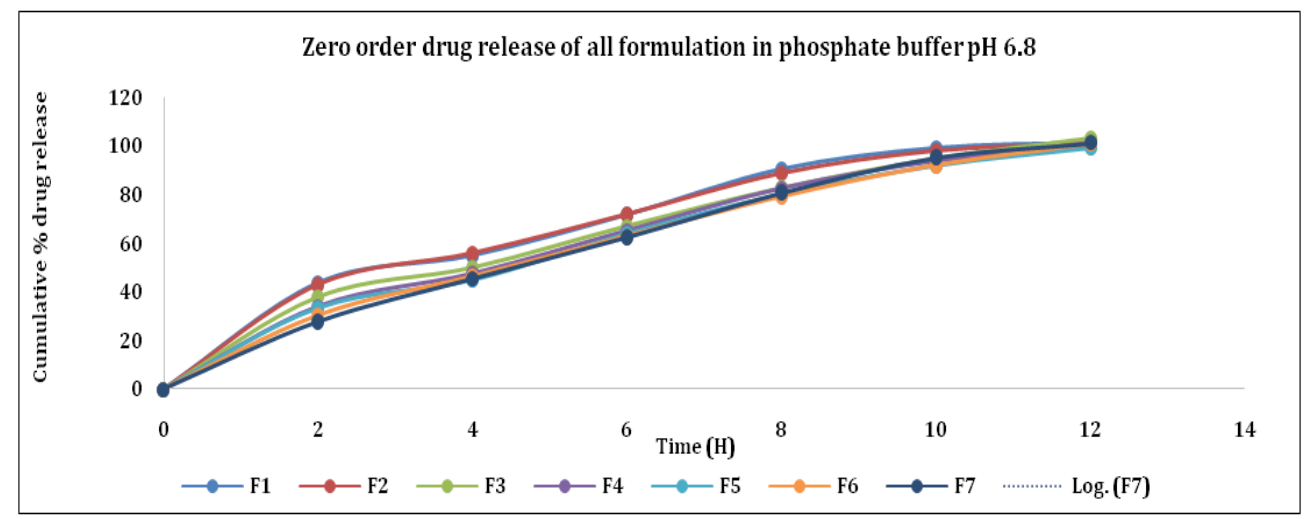

Fig. 2: Plot of zero order drug release

Table 6: First order drug release

\begin{tabular}{|c|c|c|c|c|c|c|c|}
\hline \multirow{2}{*}{$\begin{array}{l}\text { Time } \\
\text { (h) }\end{array}$} & \multicolumn{7}{|c|}{ Log \% drug remaining } \\
\hline & F1 & F2 & F3 & F4 & F5 & F6 & F7 \\
\hline 0 & 0 & 0 & 0 & 0 & 0 & 0 & 0 \\
\hline 2 & 1.805 & 1.810 & 1.837 & 1.857 & 1.860 & 1.875 & 1.886 \\
\hline 4 & 1.737 & 1.731 & 1.769 & 1.784 & 1.799 & 1.791 & 1.795 \\
\hline 6 & 1.610 & 1.610 & 1.650 & 1.665 & 1.674 & 1.682 & 1.684 \\
\hline 8 & 1.402 & 1.429 & 1.501 & 1.504 & 1.529 & 1.540 & 1.523 \\
\hline 10 & 1.257 & 1.284 & 1.338 & 1.356 & 1.381 & 1.381 & 1.328 \\
\hline 12 & 1.210 & 1.228 & 1.171 & 1.240 & 1.257 & 1.228 & 1.216 \\
\hline
\end{tabular}




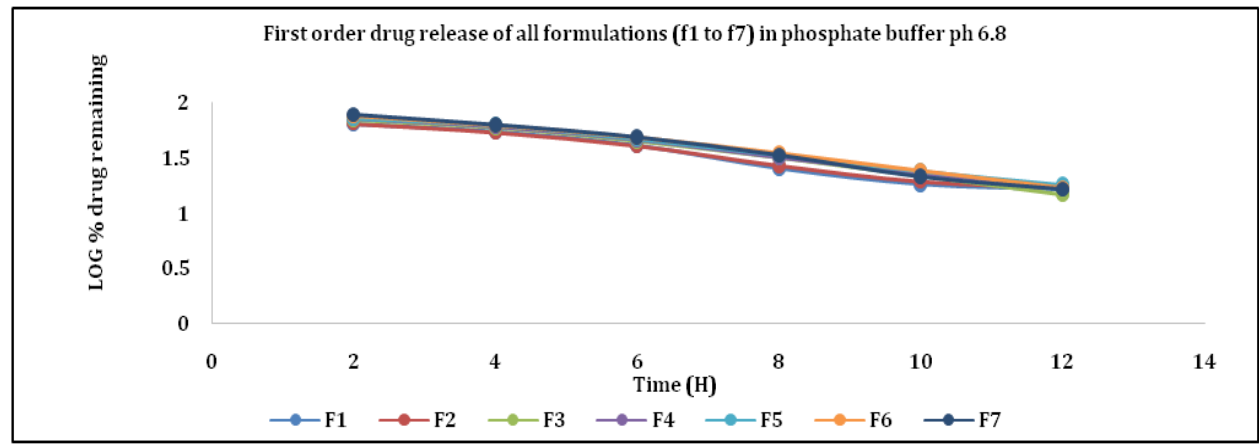

Fig. 3: Plot of first order drug release

Table 7: Higuchi plot

\begin{tabular}{|c|c|c|c|c|c|c|c|}
\hline \multirow[t]{2}{*}{ Sqrt time } & \multicolumn{7}{|c|}{ Cumulative \% drug release } \\
\hline & F1 & F2 & F3 & F4 & F5 & F6 & F7 \\
\hline 0 & 0 & 0 & 0 & 0 & 0 & 0 & 0 \\
\hline 1.414 & 43.681 & 42.841 & 37.801 & 33.881 & 33.321 & 30.241 & 27.721 \\
\hline 2 & 54.882 & 55.722 & 49.842 & 47.322 & 44.801 & 46.202 & 45.362 \\
\hline 2.449 & 71.683 & 71.683 & 66.922 & 64.962 & 63.842 & 62.722 & 62.442 \\
\hline 2.828 & 90.443 & 88.483 & 82.603 & 82.323 & 80.083 & 78.963 & 80.643 \\
\hline 3.162 & 99.124 & 97.724 & 94.644 & 93.524 & 91.844 & 91.844 & 95.204 \\
\hline 3.464 & 101.364 & 100.524 & 103.044 & 99.964 & 99.124 & 100.524 & 101.084 \\
\hline
\end{tabular}

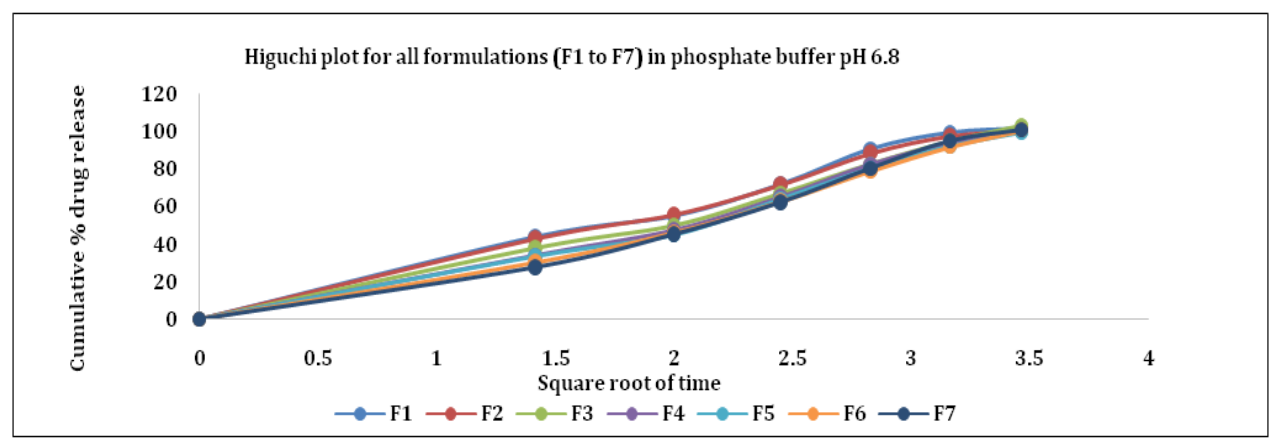

Fig. 4: Higuchi plot for all formulations

Table 8: Peppas plot for all formulation (F1 to F7) in phosphate buffer pH 6.8

\begin{tabular}{|c|c|c|c|c|c|c|c|}
\hline \multirow[t]{2}{*}{ Log time } & \multicolumn{7}{|c|}{ Log \% drug release } \\
\hline & F1 & F2 & F3 & F4 & F5 & F6 & F7 \\
\hline 0 & 0 & 0 & 0 & 0 & 0 & 0 & 0 \\
\hline 0.301 & 1.557 & 1.549 & 1.494 & 1.447 & 1.439 & 1.397 & 1.360 \\
\hline 0.602 & 1.656 & 1.663 & 1.614 & 1.592 & 1.568 & 1.581 & 1.573 \\
\hline 0.778 & 1.772 & 1.772 & 1.742 & 1.729 & 1.722 & 1.7146 & 1.712 \\
\hline 0.903 & 1.873 & 1.864 & 1.834 & 1.832 & 1.820 & 1.814641 & 1.823 \\
\hline 1 & 1.913 & 1.907 & 1.893 & 1.888 & 1.880 & 1.880266 & 1.895 \\
\hline 1.079 & 1.923 & 1.919 & 1.930 & 1.917 & 1.913 & 1.919486 & 1.921 \\
\hline
\end{tabular}

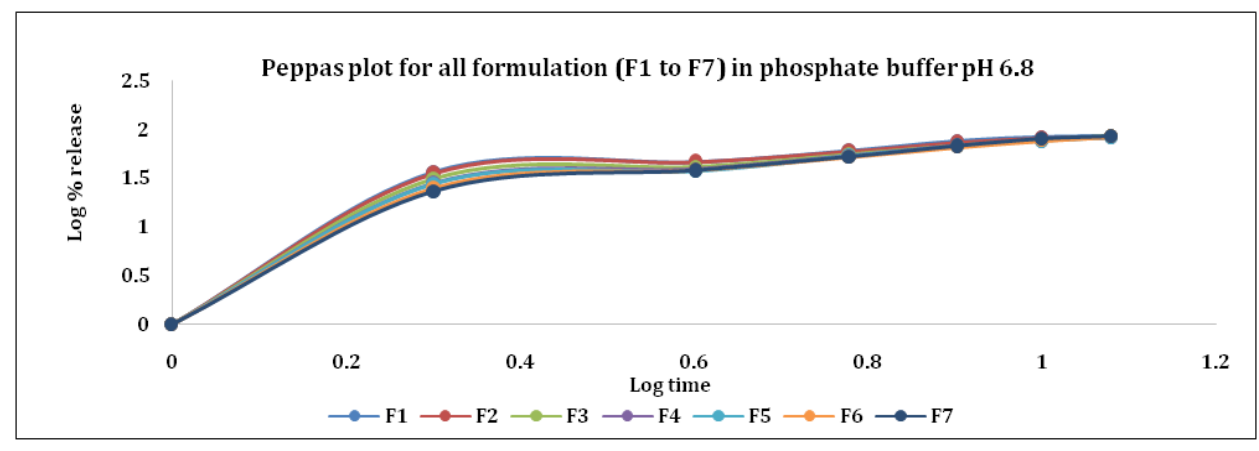

Fig. 5: Peppas plot for all formulations 
Table 9: Comparative dissolution study with BIGOMET SR500 tablet (Marketed product)

\begin{tabular}{lll}
\hline Time (h) & F7 & BIGOMET SR 500 \\
\hline 0 & 0 & 0 \\
2 & 27.72122525 & 23.80105198 \\
4 & 45.36200495 & 43.96194307 \\
6 & 62.4427599 & 64.96287129 \\
8 & 80.64356436 & 82.60365099 \\
10 & 95.20420792 & 91.28403465 \\
12 & 101.0844678 & 100.5244431 \\
\hline
\end{tabular}

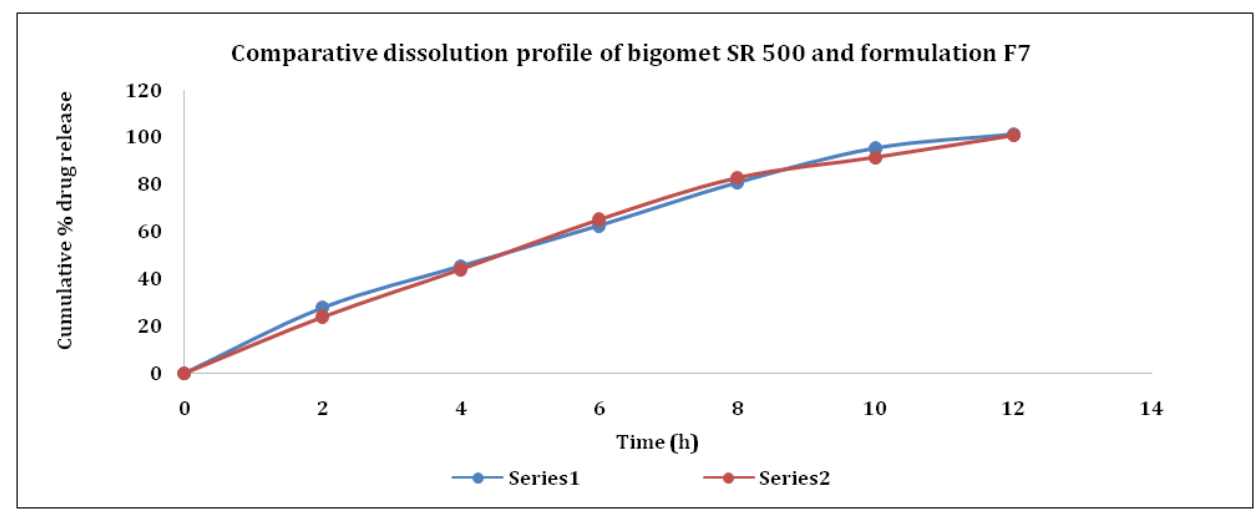

Fig. 6: CDP of bigomet SR $500 \mathrm{v} / \mathrm{s}$ formulation F7

The similarity factor (f2) as defined by FDA is the logarithmic reciprocal square root transformation of sum of squared error and is a measurement of the similarity in the percentage (\%) dissolution between the two curves [3, 4].

$$
\mathrm{f} 2=50 \log \left\{\left[1+1 / \mathrm{n} \sum_{\mathrm{n}=1^{\mathrm{n}}}\left(\mathrm{R}_{\mathrm{t}}-\mathrm{T}_{\mathrm{t}}\right)^{2}\right]^{0.5 * 100\}}\right.
$$

Results of similarity factor (f2) is $55 \%$

Where, $\mathrm{f}_{2}$ is similarity factor, $\mathrm{n}$ is the number of observations, wt. is optional weight, $R_{t}$ is average percentage drug dissolved from reference formulation and $\mathrm{T}_{\mathrm{t}}$ is average percentage drug dissolved from test formulation.

The difference factor f1 calculates the percent (\%) difference between the two curves at each time points and is the, measurement of the relative error between the two curves:

$$
\mathrm{f} 1=\left\{\left[\sum_{\mathrm{t}=1^{\mathrm{n}}}\left|\mathrm{R}_{\mathrm{t}}-\mathrm{T}_{\mathrm{t}}\right|\right] /\left[\sum_{\mathrm{t}=1^{\mathrm{n}}} \mathrm{R}_{\mathrm{t}}\right]\right\} * 100
$$

Results of difference factor (f1) is 3.5\%

\section{CONCLUSION}

Sustained release matrix tablets of metformin hydrochloride were prepared using HPMCK4M alone and in combination with Xanthan gum by wet granulation method. The results of the present study demonstrates that the HPMC K4M alone could not control the metformin hydrochloride release effectively for $12 \mathrm{~h}$, whereas when combined with Xanthan gum and it could control the release of metformin hydrochloride from their matrices. It is concluded that sustained release of metformin hydrochloride over a period of $12 \mathrm{~h}$ was obtained with formulation (F5, F6 and F7) containing Xanthan gum and HPMCK4. Out of these three formulation F7 shows the best results. Both physical parameters and drug release kinetics showed satisfactory result in formulation F7. The drug release mechanism from the matrix tablets follows Fickian diffusion with first order kinetics. The comparative dissolution profile shows satisfactory results of similarity and difference factor of test product against the reference sample. Thus, Sustained release matrix tablets of metformin hydrochloride can be expected to reduce the frequency of administration and decrease the dose dependent side effects associated with repeated administration of conventional metformin hydrochloride tablets. In vivo study of test product needs to be performed in future to study the in vivo in vitro correlation ship of test sample.

\section{FUNDING}

Nil

\section{AUTHORS CONTRIBUTIONS}

All the authors have contributed equally.

\section{CONFLICTS OF INTERESTS}

Declared none

\section{REFERENCES}

1. Brahmankar DM, Jaiswal SB. Biopharmaceutics and pharmacokinetics a treatise. 1st ed. New Delhi: Vallabh Prakashan; 1995.

2. Chein YW. Noval drug delivery systems. 2nd ed. New York: Marcel Dekker; 1992. p. 1-42.

3. Jain NK. CBS publishers and distributors. 1st ed. New Delhi: Pharmaceutical Product Development; 2006. p. 419-24.

4. Vyas SP, Khar RK. Controlled drug delivery concepts and advances. 1st ed. New Delhi: Vallabh Prakashan; 2010. p. 1-12.

5. Robinson JR, Lee VHL. Controlled drug delivery: fundamentals and applications. 2nd ed. New York: Marcel Dekker; 1987. p. 253-60.

6. Lalla JK. Introduction to controlled release and oral controlled drug delivery system. East Pharm. 1991;45:25-8.

7. Jantzen GM, Robinson JR. Morden pharmaceutics. 4th ed. New York: Marcel Dekker; 1996. p. 492-520.

8. Modi SA, Gaikwad PD, Bankar VH, Pawar SP. Sustained release drug delivery system: a review. Int J Pharm Res Dev. 2011;2(12):147-60.

9. Lieberman HA, Lachman L, Schwartz JB. Pharmaceutical dosage forms: tablets. 2nd ed. Vol. 3. p. 199-287.

10. Aulton ME. Pharmaceutics: the science of dosage form design. 2nd ed. Churchill Livingstone; 2005. p. 296-8.

11. Sastry SV, Nyshadham JR, Fix JA. Recent technological advances in oral drug delivery- a review. Pharm Sci Technol Today. 2000;3(4):138-45. doi: 10.1016/s1461-5347(00)00247-9, PMID 10754543.

12. Mahesh Hemnani, Upendra Patel, Ghanshyam Patel, Dhiren Daslaniya, Amarish Shah, Bhavin Bhimani. Matrix tablets: a tool of controlled drug delivery. Am J Pharm Tech Res. 2011;1(4):127-43. 
13. Bradoo R, Shahani S, Poojary S, Deewan B, Sudarshan S. Fast dissolving drug delivery systems. JAMA India. 2010;4:27-31.

14. Indian pharmacopoeia. Ghaziabad, New Delhi: government of India, Ministry of Health and Family Welfare; 2007.

15. Wise DL. Handbook of pharmaceutical controlled release technology. 1st ed. New York: Marcel Dekker, Inc; 2005. p. 5-24.
16. Kamboj S, Gupta GD. Matrix tablets: an important tool for oral controlled-release dosage forms. Pharm Rev. 2009;7(6);1.

17. Eswaraiah C, Jaya S. Formulation and in vitro evaluation of metformin hydrochloride sustained release tablets. J Drug Delivery Ther. 2019;9(4):24-9. 